\title{
Psychological disturbances in adolescents with acute voluntary poisoning
}

\author{
Viorela Nitescu' ${ }^{1}$ Dora Boghitoiu², Coriolan Ulmeanu \\ ${ }_{1}^{1}$ Pediatric Poisoning Centre Emergency Clinical Hospital for Children \\ "Grigore Alexandrescu", Bucharest, Romania \\ 2"Carol Davila" University of Medicine and Pharmacy, Bucharest, Romania
}

\begin{abstract}
Objective. The present study has two main objectives: to evaluate the psychological characteristics of adolescents with voluntary acute poisoning in a pediatric toxicology department and to estimate the role of psychological evaluation in the management of these patients.

Material and method. The study includes the retrospective analysis of all patients with voluntary acute intoxication, admitted to our clinic between October 1, 2017 and September 30, 2018. The following criteria were considered: age, gender, number of hospitalizations with this diagnosis and psychological evaluation. performed during hospitalization.

Results. During the mentioned period, in the Toxicology and Intensive Care Department of the Emergency Clinical Hospital for Children "Grigore Alexandrescu" in Bucharest, 181 patients were admitted with the diagnosis of voluntary acute poisoning, aged between 10 and 18 years. There was a similar percentage of girls compared to boys $(58.1 \%$ compared to $41.9 \%$ ), and most patients $(n=137,75.7 \%$ ) were from urban areas. Of the total number of patients 22 $(12.1 \%)$ had two or more hospitalizations with the diagnosis of voluntary acute intoxication. In 13 cases $(7.2 \%)$, patients were known to have previous psychiatric disorders: 8 patients with depression, 2 with behavioral disorder and 3 with disorders associated with chronic substance abuse. Analyzing the results of the psychological evaluation in these patients we found that the main psychological disorder was the emotional reaction, being identified in 98 patients $(54.1 \%)$. The suicide attempt was identified in only 31 patients $(17.1 \%)$ of whom only 10 received the transfer recommendation in a psychiatric clinic.

Conclusions. Psychological evaluation of patients with acute voluntary intoxication is essential during hospitalization in the toxicology section to identify real psychological problems. Emotional reaction is the main psychological disorder in patients with acute voluntary intoxication. The actual suicide attempt is found only in a relatively small number of patients, in our study being diagnosed only at $17 \%$ of the total voluntary acute poisoning.
\end{abstract}

Keywords: psychiatric, poisoning, adolescents, psychologic

\section{INTRODUCTION}

Acute voluntary poisoning in adolescents represents an important problem in a pediatric poisoning center requiring a complex approach which consists beside the toxicologist's intervention a psychological evaluation of the patients. Because after the poisoning treatment the result is a recovered patient but remain his psychological problems and the question if the patient need or not a psychiatric intervention or the admission in a psychiatric clinic.

The objectives of our study were to evaluate the psychological characteristics of the adolescents with acute voluntary poisoning admitted in our poisoning centre and to estimate the role of psychological evaluation in the management of these patients.

\section{MATERIAL AND METHODS}

We analysed all the patients with acute voluntary poisoning admitted in the Pediatric Poisoning Centre from the the Emergency Clinical Hospital for Children "Grigore Alexandrescu" in Bucharest during one year period, between October the $1^{\text {st }} 2017$ and September $31^{\text {st }} 2018$. The following criteria were taken into consideration: age, gender, home environment, recurrences, psychological profile. Psychological profile was obtain performing psychological evalua- 
tion done by "welcoming psychologist "completed in some situations with psychiatric examination (consult).

All of these data were obtained from the patient medical documents, with the approval of the Ethics Committee and were entered into a Microsoft Excel database.

\section{RESULTS}

During the mentioned period, 181 patients with acute voluntary poisoning were admitted in our department. This number represents $26.5 \%$ out of the total of 683 adolescents with acute voluntary poisoning treated in our clinic in this period of time.

The study group included patients with ages ranging from 10 to 18 years, the mean age beeing 15.43 years old. Most of the patients $(n=124,68.5 \%)$ aged between 15 and 17 years similar results to other studies $(3,5)$. There were 22 children 14 years old and 19 patients 13 years old. Few patients belonged to the others age groups: 9-18 years old, 5-12 years and one each for 10 and 11 years old (figure 1).

Regarding the gender distribution, we noted a similar representation of the two categories: males and females with $104(58 \%)$ girls and $76(42 \%)$ boys which is comparable to data from literature $(3,5,7)$.

Analyzing the home environment we noted that the majority of the patients $137(76 \%)$ was from the urban areas.

All the 181 patients were evaluated by the "welcoming psychologist" during the hospitalization in the toxicology department. The psychological examination included: individual discussions with the patient and their parents and the use of specific tests. The aim of this evaluation was to highlight the psychological disturbances of the child with acute volun- tary poisoning and to indicate the need of psychiatrist intervention.

Thereby, the following psychological disturbances were described in adolescents with acute voluntary poisoning included in our study: emotional reactions in 98 patients, depression in 30 cases, psychological disturbances caused by chronic consumption of substances of abuse 14 cases, behavioral disturbances 13 cases, conduct disorders 11 cases, adaptation disorders 4 cases, borderline personality 4 cases, panic attack, anxiety disorders and mood disorders each 2 cases, conversion disorder 1 patient. (figure 2). The same categories of disturbances are described in other studies but their incidence is different comparable to our analyze, severe disturbances being more frequent than in our study $(3,9,17)$.

Emotional reaction was the type of disturbance noted in the majority of the cases (98 patients) meaning $54 \%$ out of the total of 181 cases. More serious psychological disturbances, that were not reactive type, were observed in the other 83 patients, depression being the most frequent involved: 30 cases.

Another analyzed parameter in this study was represented by the psychiatric antecedents of the patients. We observed that out of the total of 181 patients 13 were previously diagnosed with a psychiatric disorder as follow: depression in 8 cases, conduct disorders in 2 cases and chronic consumer of substance of abuse 3 patients (figure 3).

Regarding recurrences, within the studied group there were 22 patients at the second or more admission for acute voluntary poisoning (figure 4). Out of these 22 cases only 5 adolescents were known with a pre-existent psychiatric disorder: 3 with depression and 2 with conduct disorders. Besides these 5 patients there were another 17 adolescents without known psychiatric disorders that were hospitalized for the second time or more.

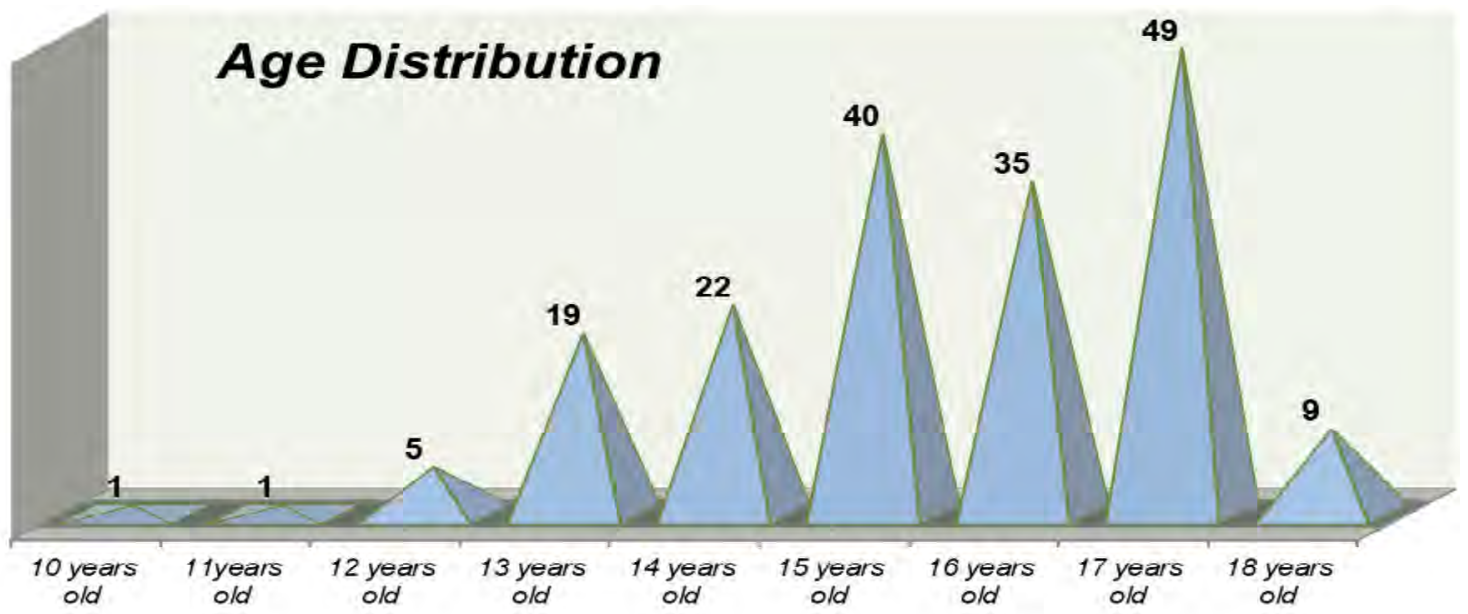

FIGURE 1. Structure of the sample by age distribution 


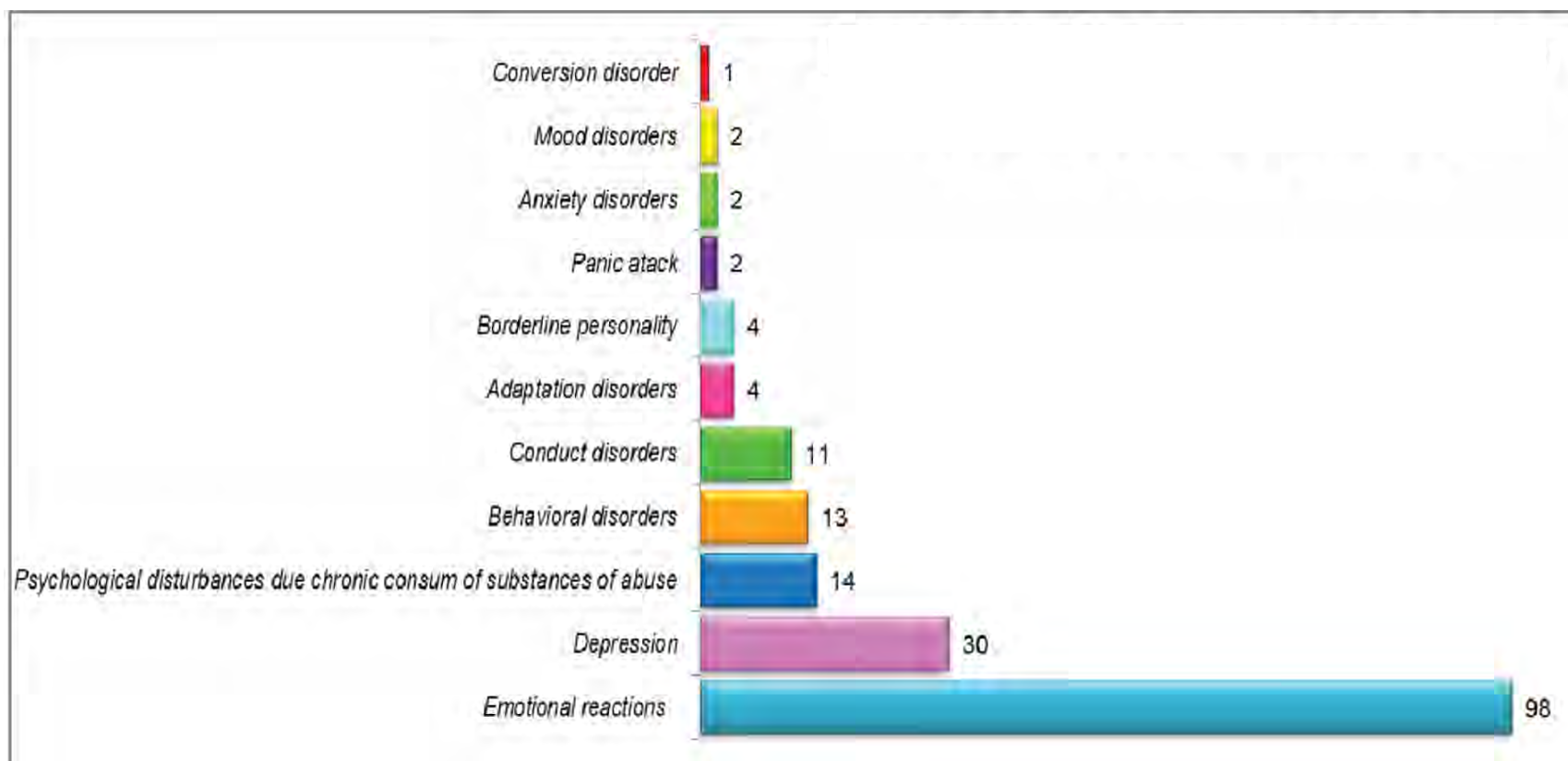

FIGURE 2. Psychological disturbances in adolescents with acute voluntary poisoning

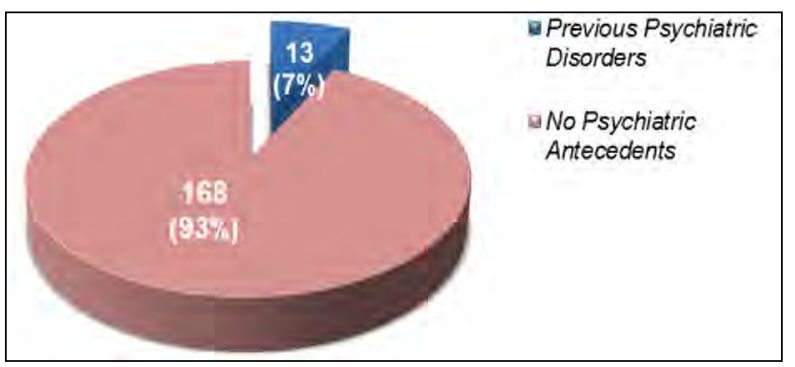

FIGURE 3. Psychiatric antecedents

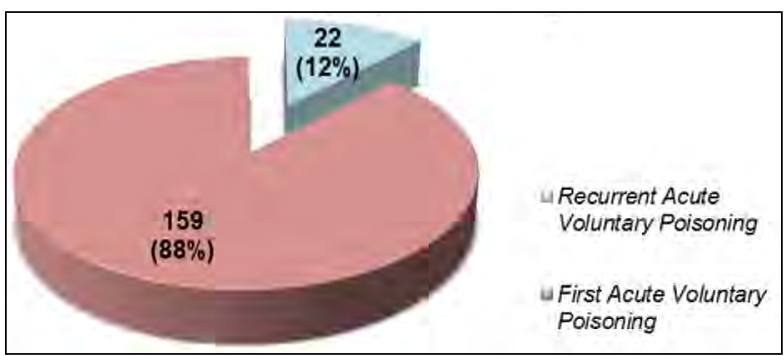

FIGURE 4. Recurrences of acute voluntary poisoning

According to the psychologist recommendation all the 98 patients with emotional reactions were not referred to the psychiatrist and were discharged with the recommendation to be psychologically counseled outside the hospital. Psychiatric consult was performed in all the others 83 cases with more serious disorders.

After the psychiatric evaluation suicidal attempt was identified in 31 patients representing $17 \%$ out of the total of 181 children with acute voluntary poisoning. The recommendation to be transferred in a psychiatric clinic was given for 10 patients (12\%) out of the total of 83 cases with more serious psychological disorders. The other 73 adolescents were discharged with the recommendation to be taken over by a psychiatrist who should establish the future therapeutic strategy which could include psychotherapy associated or not with medical treatment.

\section{DISCUSSIONS}

Acute poisoning in children, accidental or voluntary, represents a real problem of public health with an increasing incidence $(1,2)$. Detailed statistical data are provided by the Annual Report of the American Association of Antitoxic Centers, which in 2017 reported 645,000 poisonings in pediatric patients, of which $27 \%$ (171,303 cases) in the age group $13-18$ years. Of these, $63 \%$ are voluntary intoxication, classified as inadequate voluntary intakes, substance abuse or suicide attempts (3). Although mortality is not very high in the case of acute voluntary intoxication, the suicide risk is increased during the period following such an episode and remains high compared to the general population up to 10 years (4).

In adolescents and young adults, suicide through acute acute poisoning is one of the most common causes of mortality but also of morbidity, in the on-fatal cases, due to the social, economic and medical consequences that it generates in the long term (5). non-fatal suicides occur with a frequency of 10-20 times compared to attempts at death $(6,20)$. As these patients with suicidal risk can be identified following a psychological or psychiatric examination, their availability in a department of toxicology is of great importance. In the present study 31 patients (17\%) were classified, as a result of the psychiatric evaluation, as suicide attempts. 
The rest of the cases of acute voluntary intoxication appeared in patients with an affective fund of reactive type or with psychiatric pathology.

According to the psychologist, the term emotional reaction defines the act of voluntary intoxication as an "aggressive-impulsive act on the basis of age particularities and environmental stressors". In the case of adolescents it is difficult to identify the real reason that caused such a reaction (exposure to a substance with toxic potential) but numerous risk factors are identified: chronic family conflict, disorganized family, school failure, bullying in the school environment (bullying), the emotional failure or death of a close person (parent, relative or friend) (7). Female gender is also considered a risk factor for voluntary intoxication (8), although in the analyzed group we did not identify a statistically significant difference in the gender of patients.

Psychiatric pathology is also considered to be an important risk factor for both voluntary and acute poisoning, increasing the risk of suicide by 10-20 times compared to the general population (9). In the study group, psychiatric pathology was diagnosed on the occasion of hospitalization for acute intoxication in approximately half of the evaluated patients $(\mathrm{n}=83$, $45.8 \%$ ), underlining the importance of psychological evaluation in all patients with acute poisoning. Thirteen of the patients in the study group were known to have pre-existing psychiatric pathology. Depression was the most commonly diagnosed psychiatric disorder $(36.13 \%)$ in both the present study and in the specialty literature $(9,10,17)$. and one of the psychiatric disorders with an increasing incidence in adolescents $-1 \%$ of male and $2 \%$ for female (11). Another entity with an increased frequency in the analyzed group is the behavioral disorder associated with the chronic consumption of substances of abuse. It is difficult to define whether a pre-existing psychiatric pathology favors the development of addiction or the consumption of substances of abuse causes changes in the functioning of the nervous system (12), but behavioral disorders associated with the consumption increase the risk of acute intoxication and suicide, patients requiring specialist counseling (13).

As psychiatric pathology is a favorable factor for voluntary toxic exposure, in the absence of specialized psychiatric treatment the episodes of toxic exposures can be repeated $(2,20)$. It is also known that some psychotropic drugs used in children and adolescents, such as selective serotonin reuptake inhibitors, increase the risk of suicide (14) so that, once diagnosed, patients should be taken into account by pediatric psychiatry services. Of the analyzed patients 22 had multiple hospitalizations for voluntary intoxication but only 5 of them were diagnosed and treated for a pre-existing psychiatric disorder.

Although in many cases acute voluntary intoxication has a demonstrative or manipulative character $(15,18)$, without major consequences, the risk that they may signal a psychiatric illness and an evolution towards recurrence or suicide is increased.

The present study demonstrates the essential role of psychological evaluation in the selection of patients and the signaling of severe disorders that require psychiatric evaluation. Thus, the necessity of the existence and role of the welcome psychologist in the management of patients with acute voluntary intoxication is emphasized because, as we have pointed out at the beginning of the work, the complete treatment of these cases is not limited only to the treatment of acute poisoning.

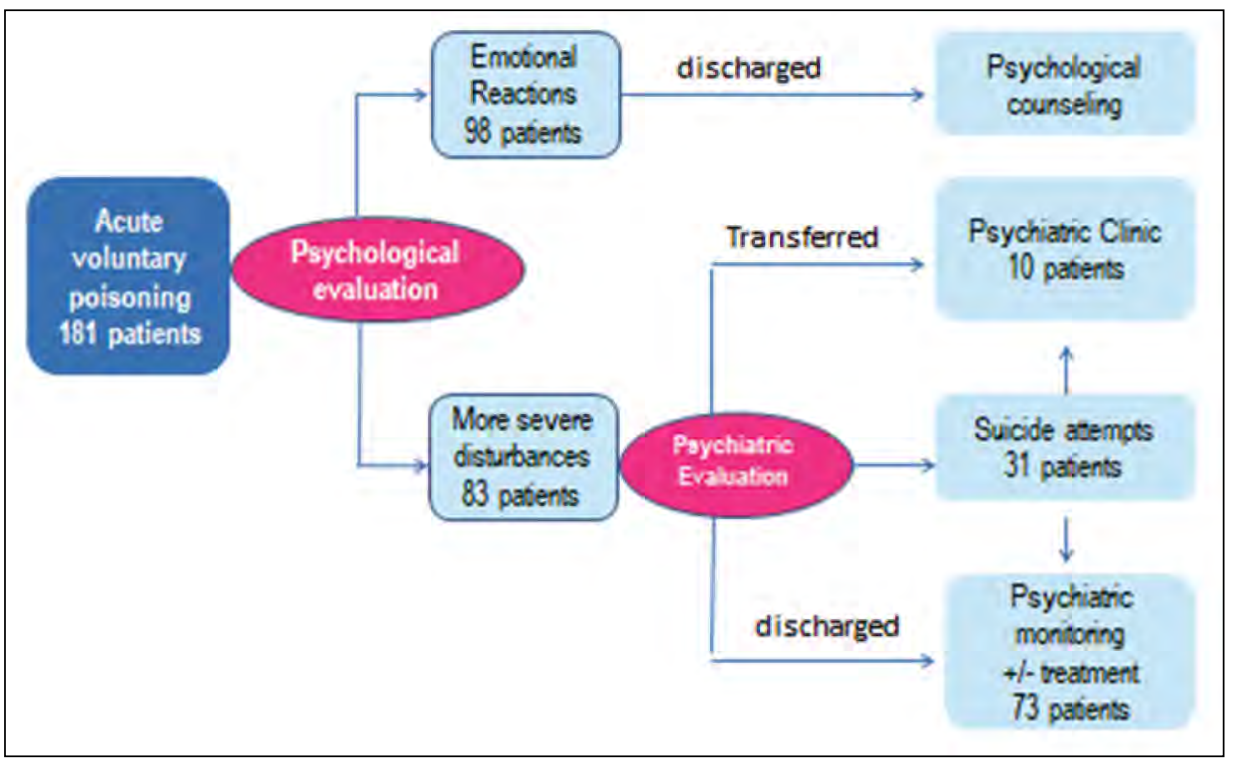

FIGURE 5. Management of voluntary acute intoxications associated with psychiatric pathology 
Based on the data obtained in this study and from literature $(16,19)$, we propose a management scheme for patients with voluntary acute intoxication depending on the psychological disorder reported (figure 5).

\section{CONCLUSIONS}

Psychological evaluation of patients with acute voluntary poisoning during the hospitalization in the

\section{REFERENCES}

1. Cutler GJ, Flood A, Dreyfus J et al. Emergency department visits for self-inflicted injuries in adolescents. Pediatrics 2015;136:28-34.

2. Bottei $E$, Abstracts $N$. Increased hospitalizations and ICU admissions in poison center cases involving teenagers. Clin Toxicol 2016;54:698.

3. Gummin DD, Mowry JB, Spyker DA et al. American Association of Poison Control Centers' National Poison Data System (NPDS): 35th Annual Report. Clin Toxicol. 2018;56 (12):1-203.

4. Finkelstein $Y$, Macdonald EM, Hollands S et al. Long-term outcomes following self-poisoning in adolescents: A population-based cohort study. Lancet Psychiatry 2015;2:532-9.

5. Zakharov S, Navratil T, Pelclova D. Non-fatal suicidal self-poisonings in children and adolescents over a 5-year period (2007-2011). Basic Clin Pharmacol Toxicol. 2013;112(6):425-430.

6. Hawton K, Arensman E, Wasserman D et al. Relation between attempted suicide and suicide rates among young people in Europe. J Epidemiol Community Health 1998;52:191-194.

7. Ulmeanu C. Tentativele de suicid la copil şi adolescent. Abordare clinică. În: Ulmeanu C, Nitescu V. Intoxicaţiile acute la copil şi adolescent. Olteniţa. Editura Tridona. 2015;3:13-16.

8. Hawton K, Witt KG, Taylor Salisbury TL et al. Interventions for self-harm in children and adolescents. Cochrane Database Syst Rev. 2015 Dec 21;(12):CD012013.

9. Nistor N, Jitareanu C, Frasinariu OE et al. Epidemiologic profile and triggering factors of voluntary poisoning in teenagers. Medicine. 2017;96(5):e5831.

10. Cipriani A, Zhou X, Del Giovane $C$ et al. Comparative efficacy and tolerability of antidepressants for major depressive disorder in children and adolescents: A network meta-analysis. Lancet 2016;388:881-890. toxicology unit is essential in identification of patients with real psychiatric problems Emotional reaction is the main psychological disturbance in adolescents with acute voluntary poisoning.

The real suicidal attempt is a serious but rarely disorder in this patients - in our study being diagnosed only in $17 \%$ out of the total of voluntary poisoning.

\section{Conflict of interest: none declared Financial support: none declared}

11. Harrington R. Depression and suicidal behaviour in children. Psychiatry. 2005;4:85-88.

12. Ross S, Peselow E. Co-occurring psychotic and addictive disorders: Neurobiology and diagnosis. Clin Neuropharmacol. 2012;35(5):235243.

13. Esang M, Ahmed S. A Closer Look at Substance Use and Suicide. The American Journal of Psychiatry Residents'. 2018;13(6):6-8.

14. Reith DM, Edmonds L. Assessing the role of drugs in suicidal ideation and suicidality. CNS Drugs 2007;21:463-472.

15. Ogundele MO. Behavioural and emotional disorders in childhood: $A$ brief overview for paediatricians. World J Clin Pediatr. 2018; 7(1): 9-26.

16. Glen CR, Nock MK. Improving the short-term prediction of suicidal behavior. AmJ Prev Med 2014;47:S176-S180.

17. Gregory BJ et al. Medical screening in the emergency department for psychiatric admissions: A procedural analysis. Gen. Hosp. Psychiatry $2004 ; 26: 405-410$.

18. McFeeters $D$ et al. Patterns of stresfull life events:distinguishing suicide ideators from suicide attempt. J. Affect. Disord. 2015; 175:192-198.

19. Broderick KB et al. Emergency physician practices and requirements regarding the medical screening examination of psychiatric patients. Acad. Emerg. Med. 2002;9:88-92.

20. Owens $D$ et al. Fatal and non-fatal repetition of self harm. Systematic review. Br J. Psychiatry. 2002;181:193-199. 